[Agr. Biol. Chem., Vol. 36, No. 2, p. 227 233, 1972]

\title{
Accumulation of 5'-Inosinic Acid and 5'-Xanthylic Acid by Bacillus subtilis
}

\author{
By Takashi AkIYA, Yuichiro Midorikawa, Akira KuninaKa, \\ Hiroshi Yoshino and Yonosuke IKEDA* \\ Research Laboratory of Yamasa Shoyu Co., Ltd., Choshi \\ * Laboratory of Microbiology, the Institute of Physical \\ and Chemical Research, Wako-shi, Saitama \\ Received July 23, 1971
}

\begin{abstract}
The accumulation of 5'-IMP or 5'-XMP by adenine-requiring or adenine-guaninerequiring mutants of Bacillus subtilis with weak $5^{\prime}$-nucleotidase was greatly increased by cultivating them at a high temperature $\left(40^{\circ} \mathrm{C}\right)$. The accumulation was markedly increased by addition of hypoxanthine or xanthine to the medium.

It is suggested that in these mutants, 5'-IMP and 5'-XMP are secondarily resynthesized through salvage pathways from their respective bases that have been accumulated first in the medium and these processes are activated at this high temperature.
\end{abstract}

Several reports have been presented concerning the direct accumulation of $5^{\prime}-\mathrm{IMP}^{1-4)}$ or $5^{\prime}-\mathrm{XMP}^{5-71}$ by bacterial mutants. In our laboratory, Fujimoto et al. ${ }^{8,91}$ previously reported that adenine-requiring mutants with weak 5'-nucleotidase of Bacillus subtilis, strain A-1 and strain A-1-25, accumulated 5'-IMP in their culture media. From further investigations on production of purine nucleotides by biochemical mutants of Bacillus subtilis, it has been concluded that the accumulation of $5^{\prime}$-IMP or $5^{\prime}$-XMP is greatly affected by cultural temperature and yields of these nucleo-

This paper was presented in parts at the symposium on Amino Acid and Nucleic Acid, December, 1968 and the Annual Meeting of the Agricultural Chemical Society of Japan, April, 1969.

The following abbreviations are used: IMP, inosine monophosphate; XMP, xanthosine monophosphate; GMP, guanosine monophosphate, AMP, adenosine monophosphate; Ino, inosine; Xao, xanthosine; Hyp, hyposanthine; Xan, xanthine; Y.E., yeast extract.

* The soybean extract was prepared as follows: Fifty-five grams of the defatted soybeans were steamed for $15 \mathrm{~min}$ in $1,000 \mathrm{ml}$ of $10 \mathrm{NaOH}$. The steamed extract was acidified to $\mathrm{pH} 4.6$ to precipitate protein and filtered. tides are evidently increased by addition of hypoxanthine or xanthine.

\section{MATERIALS AND METHODS}

Bacterial strains. Strain $A-1$, an adenine-requiring mutant with weak 5'-nucleotidase of Bacillus subtilis, was isolated by Fujimoto et al. ${ }^{81}$ previously. Strain A-1-25Z was obtained by single colony isolation from strain A-1-25.9) Strain 515 and strain AG-1023 were derived from strain $\mathrm{A}-1-25 \mathrm{Z}$ by ultraviolet irradiation and $\mathrm{N}$-methyl-N'-nitro-N-nitrosoguanidine treatment, respectively. A process of derivation of mutants is shown in Fig. 1.

Medium. The following was used as the basal culture medium; glucose $100 \mathrm{~g}, \mathrm{NH}_{4} \mathrm{Cl} 4 \mathrm{~g}$, sodium citrate $5 \mathrm{~g}, \mathrm{~K}_{2} \mathrm{HPO}_{4} 6 \mathrm{~g}, \mathrm{KCl} 1.5 \mathrm{~g}, \mathrm{MgSO}_{4} \cdot 7 \mathrm{H}_{2} \mathrm{O} 0.5 \mathrm{~g}, \mathrm{CaCl}_{2}$. $2 \mathrm{H}_{2} \mathrm{O} 0.15 \mathrm{~g}$ and yeast extract 5 to $20 \mathrm{~g}$ in $1,000 \mathrm{ml}$ of the soybean extract.* The $\mathrm{pH}$ was adjusted to 6.8 with $5 \mathrm{~N} \mathrm{NaOH}$ before sterilization.

Cultivation. Each cultivation was carried out in a $500-\mathrm{ml}$ Erlenmeyer flask containing $30 \mathrm{ml}$ of medium on a reciprocal shaker. The cultuarl temperature is indicated in each experimental result.

Analytical methods. Bacterial growth was estimated 


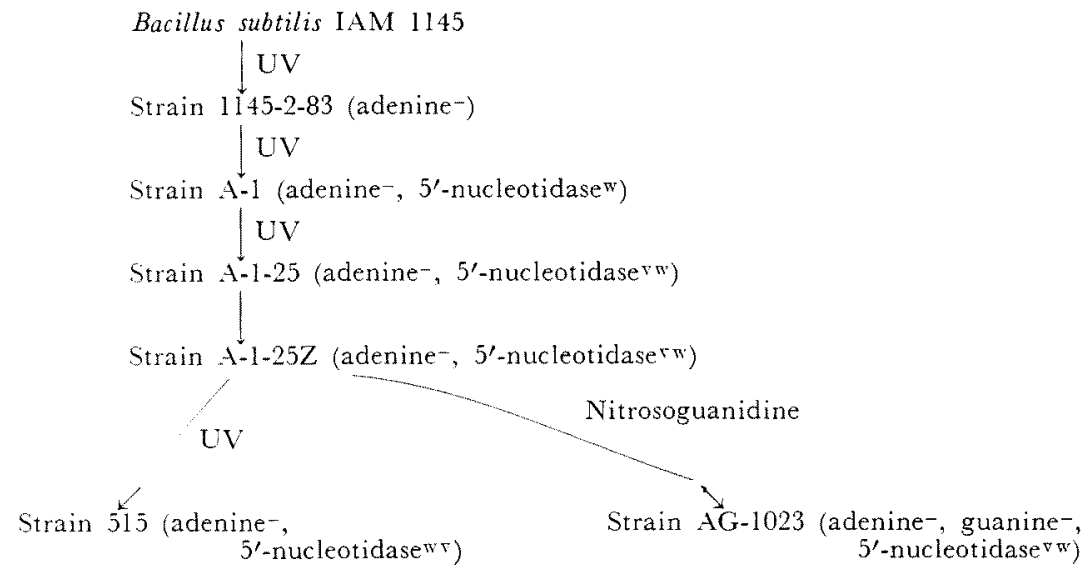

FIG. 1. Process of Derivation of Mutants

$5^{\prime}$-nucleotidasew : weak $5^{\prime}$-nucleotidase

$5^{\prime}$-nucleotidaserw: very weak $5^{\prime}$-nucleotidase

by measuring the turbidity at the wave length of 660 m.t. Determination of purine bases, nucleosides and nucleotides was made by the paper electrophoresis and paper chromatography, ${ }^{81}$

\section{RESULTS}

Accumulation of hypoxanthine derivatives at $30^{\circ} \mathrm{C}$

Figure 2 illustrates the time courses of accumulation of hypoxanthine derivatives by strain $\mathrm{A}-1$ and strain $\mathrm{A}-1-25 \mathrm{Z}$ at $30^{\circ} \mathrm{C}$ in the basal culture medium containing $5 \mathrm{~g}$ per liter of yeast extract. Compared with strain A-1, strain A-1-25Z accumulated somewhat larger amount of 5'-IMP, but did not accumulate inosine at all. Total amount of hypoxanthine derivatives accumulated by strain A-1-25Z was, therefore, much lower than that by strain A-1. In addition, the growth of strain A-1-25Z in early stage was very slow at $30^{\circ} \mathrm{C}$.

Effect of yeast extract on growth and 5-IMP accumulation

It has often been described that bacterial growth and accumulation of metabolic intermediates are closely related with each other. Fujimoto et al. ${ }^{9 \prime}$ previously reported that loss of nucleotidase activity in an adenine

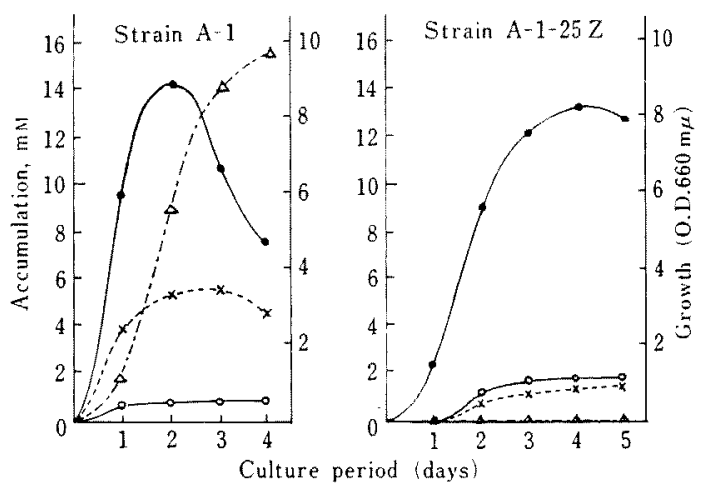

FIg. 2. Accumulation of Hypoxanthine Derivatives by Strain A-1 and Strain A-1-25Z.

Cultivation was carried out at $30^{\circ} \mathrm{C}$ by using basal culture medium containing $5 \mathrm{~g}$ per liter of yeast extract

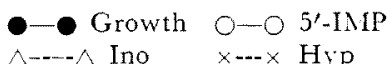

auxotroph resulted in a marked increase in the amount of adenine required for growth and that strain A-1-25 required a much larger amount of adenine or adenosine for both its growth and accumulation of hypoxanthine derivatives than strain A-I. Thus, in order to stimulate both the growth and $5^{\prime}$-IMPaccumulating ability of strain A-1-25Z, the 


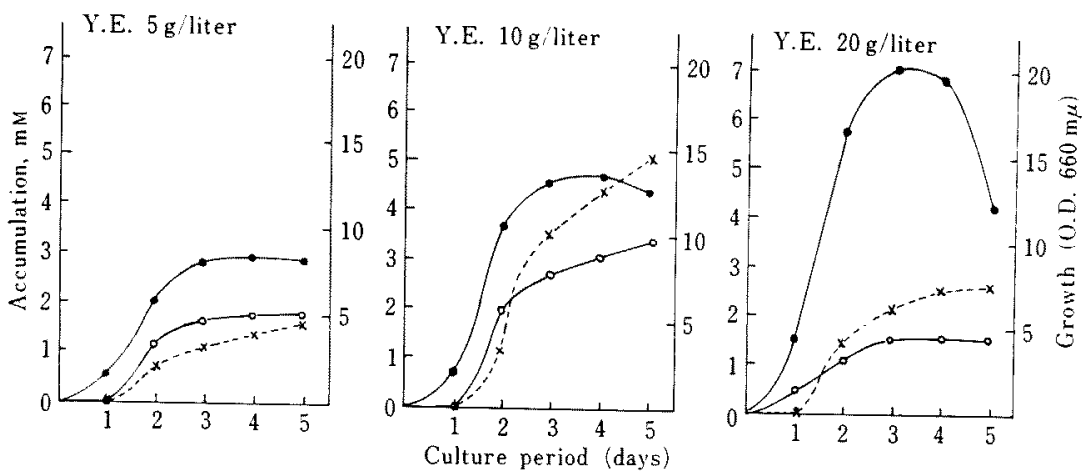

FIG. 3. Effect of Yeast Extract in the Culture Medium on Growth of Strain A-1-25Z and 5'IMP Accumulation.

Cultivation was carried out at $30^{\circ} \mathrm{C}$ by using the basal culture medium containing the amount of yeast extract indicated.

- Growth, O-O 5'-IMP, ×-.. $\times$ Hyp.

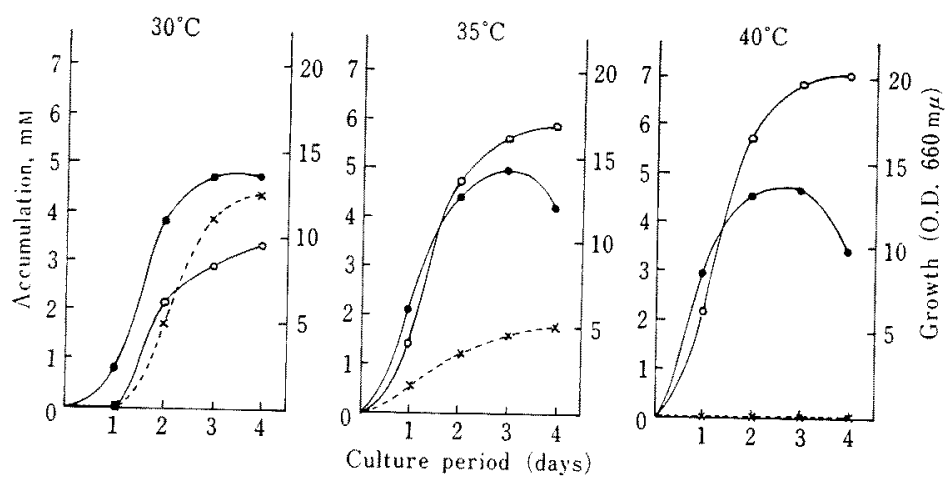

Fig. 4. Effect of Cultural Temperature on Growth of Strain A-1-25Z and 5-'IMP Accumulation.

Cultivation was carried out at the indicated temperature by using the basal culture medium containing $10 \mathrm{~g} /$ liter of yeast extract.

- Growth, O-O 5'-IMP, $x \cdots \times$ Hyp.

effect of yeast extract in the culture medium was tested. As shown in Fig. 3, large amounts of 5'-IMP and hypoxanthine were accumulated at a suitable concentration of yeast extract (10 $\mathrm{g} /$ liter) and the accumulation was repressed by the excessive addition ( $20 \mathrm{~g} /$ liter). On the other hand, although the addition of yeast extract affected the maximum growth, it did not stimulate the early growth and a long lag period was observed even in the presence of
$10 \mathrm{~g}$ or $20 \mathrm{~g}$ of yeast extract per liter.

Effect of cultural temperature on growth and $5^{\prime}$ IMP accumulation

As cultural temperature is regarded as one of main factors to stimulate bacterial growth, the effect of cultural temperature on both growth and 5 -IMP accumulation was examined by using a medium containing $10 \mathrm{~g} /$ liter of yeast extract. As shown in Fig. 4, cultural 
TABle I. EFFECT OF Yeast ExtRaCt AND TEMPERATURE ON ACCUMULATION OF HyPOXANTHINE DERIVATIVES BY STRAIN A-1-25Z

Cultivation was carried out for 5 days at $30^{\circ} \mathrm{C}$ and for 4 days at $40^{\circ} \mathrm{C}$.

\begin{tabular}{|c|c|c|c|c|}
\hline \multirow{3}{*}{$\begin{array}{l}\text { Y.E. in medium } \\
\text { (g/liter) }\end{array}$} & \multicolumn{4}{|c|}{ Accumulation after cultivation } \\
\hline & \multicolumn{2}{|c|}{ at $30^{\circ} \mathrm{C}$} & \multicolumn{2}{|c|}{ at $40^{\circ} \mathrm{C}$} \\
\hline & $\begin{array}{c}5^{\prime}-\mathrm{IMP} \\
(\mathrm{mM})\end{array}$ & $\begin{array}{l}\text { Hyp } \\
(\mathrm{mM})\end{array}$ & $\begin{array}{r}5^{\prime}-\mathrm{IMP} \\
(\mathrm{mM})\end{array}$ & $\begin{array}{l}\text { Hyp } \\
(\mathrm{mM})\end{array}$ \\
\hline 7 & 2.61 & 2.30 & 4.60 & 0 \\
\hline 10 & 2.87 & 4.32 & 7.05 & 0 \\
\hline 12 & 2.96 & 5.36 & 7.81 & 0.48 \\
\hline 15 & 2.00 & 2.05 & 3.08 & 1.16 \\
\hline
\end{tabular}

temperature affected markedly both growth and $5^{\prime}$-IMP accumulation. As cultural temperature was raised, the lag period was shortened, although the maximum growth was little affected by temperature. Raising cultural temperature also brought about a decrease of hypoxanthine accumulation and an increase of 5 -IMP accumulation. At $40^{\circ} \mathrm{C}$, hypoxanthine was not at all observed and 5'-IMP alone was accumulated. However, total amounts of hypoxanthine derivatives accumulated under these different temperatures in culture liquid were nearly constant. The similar relationship between the cultural temperature and the accumulation was generally observed irrespective of the concentration of yeast extract (Table I).

\section{Accumulation of $5^{\prime}-I M P$ by strain 515}

Further attempt was made to select more excellent mutants than strain A-1-25Z for 5'IMP accumulation and strain 515 was derived from strain A-1-25Z as one of such mutants. Table II shows the amounts of $5^{\prime}$-IMP and hypoxanthine accumulated by strain A-1-25Z and strain 515. The level of the accumulation of $5^{\prime}$-IMP by strain 515 was higher than that by strain A-1-25Z under any condition and 5'-IMP alone was accumulated by strain 515 at $40^{\circ} \mathrm{C}$ even in the medium containing the high concentration of yeast extract where both 5 -IMP and hypoxanthine were accumulated by strain A-1-25Z. Furthermore, total yield of hypoxanthine derivatives accumulated by strain 515 at $40^{\circ} \mathrm{C}$ was always greater than that at $30^{\circ} \mathrm{C}$.

\section{Effect of addition of hypoxanthine}

During cultivation of strain A-1-25Z or strain 515 , hypoxanthine was accumulated at a low temperature. As the cultural temperature was raised, gradual decrease of the amount thereof accompanied with increase of 5'-IMP accumulation was observed. This phenomenon may be explained on the assumption that $5^{\prime}$-IMP is secondarily resynthesized through salvage pathway, which is activated at a high temperature, from hypoxanthine that have been accumulated first in the medium. Thus attempts were made to test whether the accumulation of $5^{\prime}$-IMP by strain 515 would be enhanced by adding hypoxanthine to the culture medium prior to the cultivation. As shown in Table III, the accumulation of 5 -IMP was obviously increased by the addition of hypoxanthine.

Table II. ACCUMUlation of Hypoxanthine Derivatives by STrain A-1-25Z and Strain 515 Cultivation was carried out for 5 days at $30^{\circ} \mathrm{C}$ and for 4 days at $40^{\circ} \mathrm{C}$.

\begin{tabular}{|c|c|c|c|c|c|}
\hline \multirow{3}{*}{ Strain } & \multirow{3}{*}{ Y.E. in medium } & \multicolumn{4}{|c|}{ Accumulation after cultivation } \\
\hline & & \multicolumn{2}{|c|}{ at $30^{\circ} \mathrm{C}$} & \multicolumn{2}{|c|}{ at $40^{\circ} \mathrm{C}$} \\
\hline & & $5^{\prime}-\mathrm{IMP}(\mathrm{mM})$ & Hyp (mM) & $5^{\prime}$-IMP (mM) & Hyp (mM) \\
\hline \multirow{2}{*}{ A-1-25Z } & 5 & 2.03 & 1.21 & 3.16 & 0 \\
\hline & 12 & 2.98 & 4.72 & 6.88 & 1.08 \\
\hline \multirow{2}{*}{515} & 5 & 3.06 & 0 & 4.31 & 0 \\
\hline & 12 & 3.35 & 1.52 & 9.82 & 0 \\
\hline
\end{tabular}


TABle III. EFFect of AdDition of Hypoxanthine on 5'-MMP ACCUMUlation by Strain 515 Cultivation was carried out for 5 days at $30^{\circ} \mathrm{C}$ and for 4 days at $40^{\circ} \mathrm{C}$

\begin{tabular}{|c|c|c|c|c|c|c|c|}
\hline \multirow{3}{*}{$\begin{array}{l}\text { Y.E. in medium } \\
(\mathrm{g} / \text { liter })\end{array}$} & \multirow{3}{*}{$\begin{array}{l}\text { Hyp added } \\
(\mathrm{mM})\end{array}$} & \multicolumn{6}{|c|}{ Accumulation after cultivation } \\
\hline & & \multicolumn{3}{|c|}{ at $30^{\circ} \mathrm{C}$} & \multicolumn{3}{|c|}{ at $40^{\circ} \mathrm{C}$} \\
\hline & & $\begin{array}{r}5^{\prime}-\mathrm{IMP} \\
(\mathrm{mM})\end{array}$ & $\begin{array}{l}\text { Ino } \\
(\mathrm{mM})\end{array}$ & $\begin{array}{l}\text { Hyp } \\
(\mathrm{mM})\end{array}$ & $\begin{array}{l}5^{\prime}-\mathrm{IMP} \\
(\mathrm{mM})\end{array}$ & $\begin{array}{l}\text { Ino } \\
(\mathrm{mM})\end{array}$ & $\begin{array}{l}\text { Hyp } \\
(\mathrm{mM})\end{array}$ \\
\hline \multirow{2}{*}{6} & none & 4.11 & 0 & 0 & 6.75 & 0 & 0 \\
\hline & $\{20$ & 6.63 & 7.46 & 6.14 & 15.76 & 6.06 & 0.96 \\
\hline \multirow{2}{*}{10} & ( none & 4.93 & 0 & 2.96 & 9.02 & 0 & 0 \\
\hline & 20 & 6.49 & 4.20 & 13.46 & 16.62 & 4.68 & 4.20 \\
\hline
\end{tabular}

TABle IV. EFFECT of Addition of Bases on ACcumulatron of Nucleotides by Strain AG-1023 AND STRAIN A-1-25Z

The following medium was used: glucose $100 \mathrm{~g},\left(\mathrm{NH}_{4}\right)_{2} \mathrm{HPO}_{4} 5 \mathrm{~g}, \mathrm{KCl} 1.5 \mathrm{~g} \mathrm{MgSO}_{4} \cdot 7 \mathrm{H}_{2} \mathrm{O} 0.2 \mathrm{~g}$ yeast extract $5 \mathrm{~g}$ and yeast RNA $1 \mathrm{~g}$ in $1,000 \mathrm{ml}$ of soybean extract; pH 6.8 .

Cultivation was carried out for 4 days at $40^{\circ} \mathrm{C}$.

\begin{tabular}{|c|c|c|c|c|c|c|c|}
\hline \multirow[b]{2}{*}{ Strain } & \multirow[b]{2}{*}{ Base added } & \multicolumn{6}{|c|}{ Accumulation after cultivation } \\
\hline & & $\begin{array}{c}5^{\prime}-\mathrm{IMP} \\
(\mathrm{mM})\end{array}$ & $\begin{array}{c}\text { Ino } \\
(\mathrm{m} \mathrm{M})\end{array}$ & $\begin{array}{l}\text { Hyp } \\
(\mathrm{mM})\end{array}$ & $\begin{array}{l}X \mathrm{XMP} \\
(\mathrm{mM})\end{array}$ & $\begin{array}{r}\text { Xao } \\
(\mathrm{mM})\end{array}$ & $\underset{(\mathrm{m} M)}{\operatorname{San}}$ \\
\hline \multirow{3}{*}{ AG-1023 } & None & 0.9 & 0 & 0 & 4.0 & 7.8 & 0 \\
\hline & Hyp $15 \mathrm{~mm}$ & 1.6 & 0 & 0 & 7.1 & 14.4 & 3.5 \\
\hline & $\mathrm{Xan} 15 \mathrm{mM}$ & 0.6 & 0 & 0 & 7.8 & 16.3 & 2.3 \\
\hline \multirow{3}{*}{$A-1-25 Z$} & None & 7.9 & 0 & 0 & 0 & 0 & 0 \\
\hline & Hyp $15 \mathrm{mM}$ & 17.2 & 2.8 & 1.9 & 0 & 0 & 0 \\
\hline & Xan $15 \mathrm{mM}$ & 16.4 & 1.4 & 1.7 & trace & 2.0 & trace \\
\hline
\end{tabular}

Furthermore, the effect of hypoxanthine addition at $40^{\circ} \mathrm{C}$ was proved to be more evident than that at $30^{\circ} \mathrm{C}$.

Accumulation of $5^{\prime}-X M P$ by strain $A G-1023$

In our laboratory, in the course of investigations on the production of nucleic acidrelated compounds by Bacillus subtilis, it has been found that a guanine-requiring mutant has a great ability of synthesizing xanthosine from exogenous hypoxanthine ${ }^{101}$ and the further induction of adenine requirement in a guanine-requiring mutant leads to a marked increase in the ability of direct accumulation of xanthosine in the culture medium. ${ }^{11}$ So, an adenine-guanine-requiring mutant, strain $\mathrm{AG}-1023$, was derived from an adenine-requir- ing strain, A-1-25Z, and its ability of production of 5'-XMP was investigated. In the experiment in which the basal culture medium containing $10 \mathrm{~g}$ per liter of yeast extract was used, the amount of $5^{\prime}-\mathrm{XMP}$ produced at $40^{\circ} \mathrm{C}$ ( $3.02 \mathrm{mM}$ ) was about twice as much as that produced at $30^{\circ} \mathrm{C}(1.57 \mathrm{~mm})$. Table IV shows the effect of addition of hypoxanthine or xanthine to the culture medium on the accumulation of $5^{\prime}$-nucleotides by strain AG-1023 and strain A-1-25Z. The accumulation of 5'XMP by strain AG-1023 was evidently increased by adding hypoxanthine or xanthine to the culture medium. On the other hand, in the case of strain A-1-25Z, the addition of xanthine to the medium, as well as that of hypoxanthine, resulted in a marked increase 
in the amount of $5^{\prime}$-IMP.

\section{DISCUSSION}

There are a few reports concerning the participation of salvage pathway in the direct accumulation of nucleic acid-related compounds by bacterial mutants. ${ }^{11-13 !}$ Nara et al. ${ }^{13)}$ reported that $5^{\prime}$-IMP accumulation by an adenine-requiring mutant of Brevibacterium ammoniagenes might be caused by salvage synthesis from hypoxanthine which was accumulated predominantly during an early stage of the cultivation. From the present investigation, it is suggested that $5^{\prime}$-IMP and 5-XMP produced by biochemical mutants of Bacillus subtilis might also be secondary products synthesized from their respective bases which had been accumulated first. However, in these cases, the accumulation of nucleotides was observed in accordance with bacterial growth and the significant accumulation of the bases prior to that of their respective nucleotides was not observed. In the case of Bacillus subtilis, it is conceivable that salvage system may function even in an early stage of the cultivation. By what mechanism cultural temperature affects de novo synthesis and salvage synthesis of nucleotides remains to be clarified, though a high temperature is presumed to contribute to the synthesis or activation of the enzyme(s) related to production of nucleotides.

On the other hand, it is interesting that the addition of hypoxanthine to the culture medium, as well as that of xanthine, increased the accumulation of $5^{\prime}$-XMP by an adenine-guanine-requiring mutant, while the addition of xanthine, as well as that of hypoxanthine, increased the accumulation of 5'-IMP by an adenine-requiring mutant. These results may be understood on the basis of genetic property of mutant with or without the depletion of 5'-GMP synthetase as shown in Fig. 5. Present investigation suggests that the accumulation of other nucleotides by Bacillus subtilis in the i) Strain A-1-25 Z, Strain 515

\section{Accumulation}

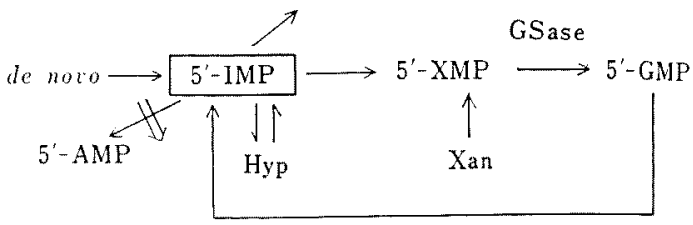

ii) Strain $A G-1023$

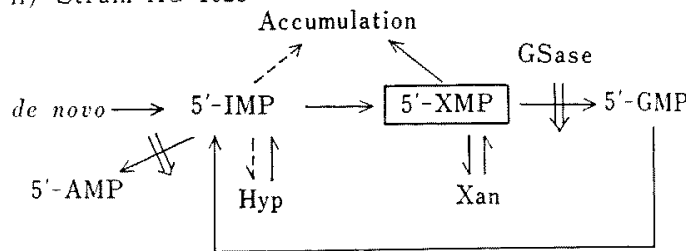

GSase : 5'-GMP synthetase

$\longrightarrow$ : genetic block

FIG. 5. Possible Route of Accumulation of 5/-IMP and $5^{\prime}-\mathrm{X}$ MP.

culture medium through de novo pathway or salvage pathway from various bases may be attained by the skillful use of mutation techniques. Recently, we have found that succinyl-adenylic acid is produced by an adenine-requiring mutant of Bacillus subtilis. ${ }^{14}$

\section{REFERENCES}

1) K. Uchida, A. Kuninaka, H. Yoshino and M. Kibi, Agr. Biol. Chem., 25, 804 (1961).

2) K. Nakayama, T. Suzuki, Z. Sato and S. Kinoshita, J. Gen. Appl. Microbiol., 10, 133 (1964).

3) T. Nara, M. Misawa and S. Kinoshita, Agr. Biol. Chem., 31, 1351 (1967).

4) A. Furuya, S. Abe and S. Kinoshita, Appl. Microbiol., 16, 981 (1968).

5) M. Misawa, T. Nara, K. Udagawa, S. Abe and S. Kinoshita, Agr. Biol. Chem., 28, 690 (1964).

6) A. L. Demain, M. Jackson, R. A. Vitali, D. Hendlin and T. A. Jacob, Appl. Microbiol., 13, 757 (1965).

7) M. Misawa, T. Nara, K. Ldagawa, S. Abe and S. Kinoshita, Agr. Biol. Chem., 33, 370 (1969).

8) M. Fujimoto and K. Uchida, ibid., 29, 249 (1965). 
9) M. Fujimoto, M. Morozumi, Y. Midorikawa, S. Miyakawa and K. Uchida, Agr. Biol. Chem., 29, 918 (1965).

10) M. Fujimoto and K. Uchida, ibid., 29, 1150 (1965).

11) M. Fujimoto, K. Uchida, M. Suzuki and $H$. Yoshino, ibid., 30, 605 (1966).
12) A. Hirano, T. Akimoto and T. Osawa, Nippon Nogeikagaku Kaishi, 42, 60 (1968).

13) T. Nara, M. Misawa and S. Kinoshita, Agr. Biol. Chem., 32, 561 (1968).

14) I. Midorikawa, T. Akiya, Y, Kato, T. Kiyanagi, A. Kuninaka and $\mathrm{H}$. Yoshino, ibid., in press. 